\title{
ESTUDO COMPARATIVO DE ARGAMASSAS DE REVESTIMENTO REFORÇADAS COM FIBRAS DE POLIPROPILENO
}

\author{
VICENTIN, ALINE MENEGAS DE \\ Engenheira Civil \\ Unochapecó \\ Santa Catarina; Brasil \\ alivicentin@unochapeco.edu.br
}

\author{
BATISTON, EDUARDO ROBERTO \\ Engenheiro Civil \\ Unochapecó \\ Santa Catarina; Brasil \\ erbatiston@unochapeco.edu.br
}

\author{
LASTE, JOÃO PAULO MOSCHETTA DALLE \\ Engenheiro Civil \\ Unochapecó \\ Santa Catarina; Brasil \\ joaopaulo.dallelaste@unochapeco.edu.br
}

\begin{abstract}
RESUMO
O presente artigo apresenta um estudo comparativo entre argamassas de revestimento reforçadas com fibras de polipropileno de 6 e $12 \mathrm{~mm}$ de comprimento e uma argamassa de referência sem aditivo, com objetivo de avaliar o efeito da fibra de polipropileno no combate ao surgimento de fissuras. Foram analisados os comportamentos das misturas aplicadas em painéis expostos às intempéries, sobre aspecto de fissuração, aos 28 dias, além da realização de ensaios de resistência de corpos de prova, ensaio de arrancamento, índice de consistência e umidade das amostras. Os resultados indicaram que a presença das fibras melhora o desempenho da matriz cimentícia, diminuindo efeitos de deformação, melhora o espalhamento e a aderência ao substrato, ocasionando maior resistência ao arrancamento, porém reduz a retenção de água nos compósitos. Também se observou uma diminuição de cerca de $80 \%$ no comprimento total de fissuras nos revestimentos, comparados à argamassa sem fibras. Além de ser um material leve e de baixo custo, a fibra apresenta-se como uma solução eficaz para revestimentos mais duráveis.
\end{abstract}

Palavras-chave: argamassas, fissuração, fibra de polipropileno.

\section{ABSTRACT}

This paper presents a comparative study between coating mortars reinforced with polypropylene fibers of 6 and $12 \mathrm{~mm}$ long and a reference mortar without additive, aiming to evaluate the effect of polypropylene fibers on cracking combat. It was analyzed the behavior of composites applied on panels exposes to the weather, about cracking aspect, at 28 days, besides body-prove resistance tests, extracting test, consistence and humidity index of the samples. The results indicated that the fibers improve performance of the mortars, decreasing deformation effects, improves spreading and adhesion to the substrate, causing greater extracting resistance, but reduces water retention in composites. It was also observed a decrease in about $80 \%$ in the total length of cracks in coatings, compared to the fiber-free mortar. Besides being a light and low-cost material, the fibers present as an efficient solution to more durable coatings.

Keywords: mortar, cracking, polypropylene fiber.

\section{INTRODUÇÃO}

Um dos mais importantes cartões de visita de um edifício é sua fachada. Cada vez mais altas e com diferentes tipos de textura, elas têm a função de passar uma boa primeira impressão externa de qualquer obra. Dependendo da posição geográfica das edificações, as fachadas podem sofrer mais ou menos com as ações climáticas (sol, chuva, vento), o que pode resultar em uma das patologias mais comuns em rebocos externos, a fissuração do revestimento de argamassa.

As fissuras vão surgindo aos poucos e podem ser causadas por vários fatores, desde problemas estruturais, problemas durante a execução do revestimento, até a escolha da composição e dos materiais da argamassa.

Há espaço no mercado da construção civil para inovações que tragam melhorias no desempenho dos materiais. Nesse contexto, entra o estudo de reforço com fibras poliméricas, que se apresenta como uma alternativa diminuir as 
fissurações quando aplicadas em revestimentos externos.

As fibras poliméricas podem ser produzidas a partir de diversos materiais, como: policarbonato (CDs, garrafas), polipropileno (brinquedos, recipientes), polietileno tereftalato (PET), entre outros.

É importante que tanto os materiais, como as próprias fibras, sejam corretamente escolhidos e dosados, pois do contrário, podem comprometer a qualidade da argamassa (ALMEIDA; SICHIERI, 2006).

As fibras podem ser descritas como um material leve e resistente, um aditivo confiável à argamassa, capaz de suprir os desafios de evitar a fissuração (MODRO et al., 2009).

Este trabalho teve como objetivo comparar o comportamento à fissuração de argamassas reforçadas com fibras e uma argamassa de referência (sem fibras). Foram realizadas as caracterizações das argamassas, ensaios de resistência mecânica, retenção de água e arrancamento, com objetivo de relacionar suas propriedades com a presença ou não de fissuras.

\section{MATERIAIS E MÉTODOS}

\subsection{Materiais}

As fibras poliméricas utilizadas neste estudo foram fibras comerciais de polipropileno, de $18 \mu$ m de diâmetro e com 6 e $12 \mathrm{~mm}$ de comprimento, cedidas por um representante da empresa Maccaferri do Brasil. A quantidade de fibra utilizada na argamassa seguiu as recomendações do fornecedor, de $200 \mathrm{~g}$ por saco de cimento, ou proporcional.

O cimento escolhido foi o Cimento Portland CP II-F-32, que é usual em argamassas de revestimento. A cal foi do tipo hidratada $\mathrm{CH}-\mathrm{III}$, muito usada em argamassas de revestimento.

Para o agregado miúdo, foi utilizado areia natural de leito de rio, fina, devido à disponibilidade na região. A composição em volume de materiais secos escolhido foi 1:1:3 (THOMAZ 2001 apud PINTO; FIORITI, 2016), conforme Tabela 1.

Tabela 1 - Composições das argamassas

\begin{tabular}{c|c|c|c}
\hline Mistura & Referência & Fibra $6 \mathrm{~mm}$ & Fibra $12 \mathrm{~mm}$ \\
\hline Cimento $(\mathrm{Kg})$ & 7 & 7 & 7 \\
\hline Cal $(\mathrm{Kg})$ & 7 & 7 & 7 \\
\hline Areia $(\mathrm{Kg})$ & 21 & 21 & 21 \\
\hline Fibra $(\mathrm{g})$ & - & 28 & 28 \\
\hline
\end{tabular}

\subsection{Métodos}

As características do agregado foram obtidas seguindo as orientações da NBR 7217 (ABNT, 1987). De acordo com a NBR 7211 (ABNT, 2009), areia utilizada foi classificada como fina (módulo de finura = 1,43).

O principal método experimental realizado baseou-se nos estudos de Pinto e Fioriti (2016), que consistiu no preparo de painéis de alvenaria e posterior ensaio de susceptibilidade à fendilhação, que não segue norma específica, e que consistiu em uma observação visual à argamassa de revestimento aplicada nos painéis, por um período de 28 dias, de modo a detectar a existência de fissuras.

O local para o levantamento dos painéis foi escolhido de forma que os mesmos tivessem a orientação solar Leste-Oeste em cada uma das faces. Foram utilizados tijolos de 9 furos com as dimensões 24x19x11,5 cm (comprimento versus altura versus largura). Para esta etapa, foi utilizada argamassa pronta para assentamento, sendo necessária somente a adição de água.

Antes do levantamento da primeira fiada, foram corretamente posicionados os blocos com auxílio de bússola, e cada painel para que os mesmos não fizessem sombra para os demais. Foram levantados ao todo 6 painéis com dimensões $60 \times 50 \mathrm{~cm}$ (altura versus comprimento), conforme Figura 1, com juntas verticais e horizontais de $2 \mathrm{~cm}$. 


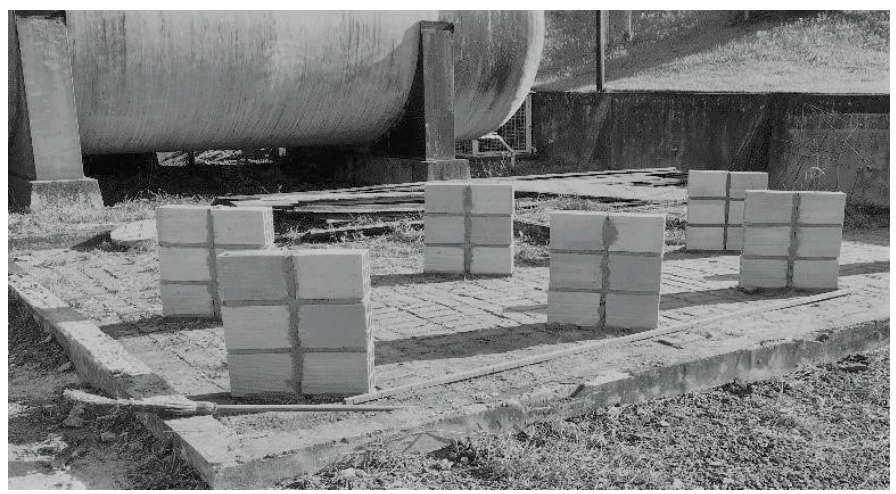

Figura 1: Painéis em alvenaria aparente

Após 28 dias de cura, realizou-se o chapisco, o qual foi preparado com os mesmos materiais escolhidos para o revestimento. Após 14 dias de cura do chapisco, realizou-se o revestimento dos painéis. Foram preparadas três argamassas na betoneira, com os materiais escolhidos: Cimento Portland CP II-F-32, Cal Hidratada CH-III e areia fina, na composição 1:1:3, e água, acrescentada aos poucos até se obter uma mistura trabalhável.

A primeira argamassa não contou com adição de fibra. Com a mesma, foram revestidos dois painéis em ambas as faces. A espessura do revestimento, foi fixada em $1,5 \mathrm{~cm}$ para todos os painéis, indiferente da argamassa.

As próximas duas misturas receberam adição das fibras de polipropileno de $6 \mathrm{~mm}$ e $12 \mathrm{~mm}$, nas proporções recomendadas pelo fabricante. Foram revestidos outros dois painéis, para cada argamassa, com seu respectivo comprimento de fibra. Os procedimentos foram realizados da mesma forma. Para cada uma das argamassas produzidas, foi retirado uma amostra e imediatamente levada para laboratório para realização do ensaio de consistência (flow table), e confecção dos corpos de prova para posterior ensaios de resistência à compressão e resistência à tração na flexão.

O índice de consistência de cada mistura foi obtido a partir da NBR 13276 (ABNT, 2002), que corresponde à média dos diâmetros de três pontos distintos na mesa de flow.

Para os ensaios de resistência mecânica, foram preparados corpos de prova $(\mathrm{CP})$ cilíndricos e prismáticos (3 de cada para cada mistura), seguindo as orientações da NBR 7215 (ABNT, 1996) e NBR 13279 (ABNT, 2005), respectivamente.

Após 24h, os corpos de prova foram desformados, e em seguida deixados para a cura de 28 dias ao ar livre. Posteriormente ao término do tempo de cura, os 18 corpos de prova foram submetidos aos ensaios de resistência mecânica, em máquina universal de ensaios. Antes, foi verificado a massa e as dimensões de todos os CPs, com o auxílio de um paquímetro digital.

O ensaio de resistência de aderência à tração foi realizado de acordo com a NBR 13528 (ABNT, 2010), após 28 dias do revestimento dos painéis. Foram realizados 16 ensaios para cada argamassa. A taxa de carregamento adotada foi de 5 $\mathrm{N} / \mathrm{s}$, de acordo com a norma e com base na resistência de aderência da primeira pastilha, que foi inferior a 0,20 Mpa.

Ao final do ensaio, foram coletadas três amostras de cada argamassa, as quais foram aferidas as massas, identificadas e colocadas na estufa por $24 \mathrm{~h}$, a uma temperatura de $105^{\circ} \mathrm{C}$. Após, aferiu-se novamente a massa das amostras, afim de obter a porcentagem de umidade contida em cada uma delas.

\section{RESULTADOS E DISCUSSÃO}

A partir dos dados obtidos do ensaio de índice de consistência (flow table), fez-se a determinação da média dos pontos, conforme apresentado na Tabela 2.

Verificou-se que, enquanto as argamassas de referência e com fibra de $12 \mathrm{~mm}$ apresentaram índices próximos entre si, a argamassa contendo fibra de $6 \mathrm{~mm}$ apresentou o menor índice de consistência, indicando, portanto, que esta argamassa tem menor facilidade de se deformar sob ação de cargas. Isto se deve à boa aderência deste comprimento de fibra com a matriz cimentícia. 
Tabela 2 - Índice de consistência das argamassas

\begin{tabular}{c|c|c|c}
\hline Medidas (mm) & $\begin{array}{c}\text { Argamassa de } \\
\text { referência }\end{array}$ & Argamassa com fibra de 6 mm & Argamasssa com fibra de $12 \mathrm{~mm}$ \\
\hline Média & 257,69 & 229,74 & 270,25 \\
\hline Desvio Padrão (DP) & 0,17 & 3,18 & 4,51 \\
\hline
\end{tabular}

Os resultados dos ensaios de resistência mecânica realizados nos corpos de provas podem ser observados na Tabela 3 , bem como o desvio padrão respectivo.

Tabela 3 - Resistência mecânica das amostras

\begin{tabular}{c|c|c|c|c}
\hline \multirow{2}{*}{ Ensaio } & \multicolumn{3}{|c|}{ Argamassa } & \multirow{2}{*}{ Desistência mecânica Padrão (DP) } \\
\cline { 2 - 4 } & Referência & Fibra 6 mm & Fibra 12 mm & 0,45 \\
\hline Tração na flexão (prismático) & 3,01 & 2,73 & 2,11 & 1,79 \\
\hline Compressão axial (prismático) & 9,77 & 7,26 & 6,29 & 0,80 \\
\hline Compressão axial (cilíndrico) & 5,50 & 6,82 & 5,38 & \\
\hline
\end{tabular}

Pôde-se notar que, nos ensaios de resistência à tração na flexão e compressão axial, os corpos de prova prismáticos com argamassa de referência foram os que apresentaram os melhores resultados, seguidos pelos corpos de prova contendo argamassa com fibras de $6 \mathrm{~mm}$.

No entanto, na compressão de corpos de prova cilíndricos, os que continham argamassa com fibra de $6 \mathrm{~mm}$ foram os que alcançaram as maiores resistências, seguidos então, pelos que continham argamassa de referência. Para os três ensaios, a argamassa que continha fibra de $12 \mathrm{~mm}$ apresentou os piores resultados. $\mathrm{O}$ ensaio de compressão axial com CPs prismáticos foi o que apresentou maior desvio padrão.

Após a análise dos dados do ensaio de arrancamento, foram determinadas às resistências de aderência à tração para as argamassas. Foram também analisados os tipos de ruptura mais observados entre os corpos de prova. Em resumo, entre os CP dos painéis com argamassa de referência, a forma de ruptura mais observada foi na interface revestimento/cola, representando $38 \%$ das pastilhas.

Nos painéis com fibras de $6 \mathrm{~mm}$ observou-se predominância de rupturas do revestimento, com uma parcela de ruptura do substrato, em $50 \%$ das pastilhas consideradas. Já, nos painéis com fibras de $12 \mathrm{~mm}$, houve predominância de rupturas do substrato, com uma parcela de ruptura do revestimento, em $38 \%$ das pastilhas. Rupturas na interface cola/pastilha foram desprezadas nesta análise, conforme recomendação da norma.

As resistências máximas e médias calculadas entre os corpos de prova são apresentadas na Tabela 4. Para o cálculo da resistência média também foram desconsiderados os corpos de prova com rupturas na interface cola/pastilha.

Tabela 4 - Resistência máximas e médias entre os CPs

\begin{tabular}{c|c|c|c}
\hline \multicolumn{4}{|c}{ Resistência de aderência à tração (MPa) } \\
\hline Argamassa & Resistência Máxima & Resistência Média & Desvio Padrão (DP) \\
\hline Referência & 0,41 & 0,20 & 0,02 \\
\hline Fibra 6mm & 0,99 & 0,44 & 0,02 \\
\hline Fibra 12mm & 0,80 & 0,34 & 0,03 \\
\hline
\end{tabular}

Por meio das amostras retiradas dos painéis, observou-se que as amostras de referência apresentaram uma média de 6,60\% de umidade, enquanto as amostras com fibras de $6 \mathrm{~mm}$ e $12 \mathrm{~mm}$, apresentaram umidade média entre 5,00\% e $5,40 \%$, respectivamente, conforme apresentado na Tabela 5, o que indica que as fibras, sujeitas de forma igual às condições climáticas, contribuem para a redução da absorção de água, confirmando as afirmações de Pimentel et al. (2006). 
Tabela 5 - Índice de unidade das amostras

\begin{tabular}{c|c|c|c}
\hline Argamassa & $\mathrm{N}^{\mathrm{o}}$ de Amostras & $\begin{array}{c}\text { \% Umidade } \\
\text { Média }\end{array}$ & $\begin{array}{c}\text { Desvio Padrão } \\
\text { (DP) }\end{array}$ \\
\hline Referência & 3 & 6,60 & 0,41 \\
\hline Fibra $6 \mathrm{~mm}$ & 3 & 5,00 & 0,51 \\
\hline Fibra $12 \mathrm{~mm}$ & 3 & 5,40 & 0,90 \\
\hline
\end{tabular}

O ensaio de susceptibilidade à fendilhação consistiu num monitoramento aos painéis, a partir do dia seguinte à aplicação do revestimento, por um período de 28 dias, para acompanhar o surgimento de fissuras.

Logo no primeiro dia, com a argamassa já seca, observou-se que praticamente todas as faces dos painéis apresentaram fissuras. Os painéis com argamassa de referência foram nitidamente os mais afetados, enquanto os painéis com argamassa acrescida de fibras, apresentaram fissuras mais finas.

As paredes com argamassa de fibras de $12 \mathrm{~mm}$ apresentaram pequenas "falhas" caracterizadas pelo agrupamento das fibras, mostrando que esse comprimento de fibra não parece adequado para a utilização em revestimento. As observações seguiram a cada 2 dias, sempre no período final da tarde.

A partir da quarta observação, todos os painéis contendo argamassa com fibras apresentaram estabilidade quanto ao aparecimento e expansão das fissuras, e seguiram estáveis durante todo restante do acompanhamento do ensaio. Já os painéis com argamassa de referência seguiram apresentando novas fissuras e expansões nos primeiros 15 dias, até a oitava observação, quando estes então, começaram a se estabilizar.

Nas últimas duas observações, aos 26 e 28 dias, nenhum painel apresentou novas fissuras. Os comprimentos de fissuras de cada observação foram registrados e o somatório de cada painel pode ser observado na Tabela 6 a qual apresenta um resumo do comprimento total de fissuras aos 28 dias.

O resultado visual da face mais prejudicada de um dos painéis, correspondente a cada tipo argamassa, ao final deste tempo, pode ser observado na Figura 2. Para melhor visualização, as fissuras foram desenhadas digitalmente.

Tabela 6 - Comprimento total de fissuras observadas nos painéis $(\mathrm{cm})$

\begin{tabular}{|c|c|c|c|c|c|c|c|}
\hline \multicolumn{8}{|c|}{ Painéis } \\
\hline Fachada & $1^{\circ}-$ Ref. & $2^{\circ}-$ Ref. & $\begin{array}{c}3^{\circ}-\text { Fibra } \\
6 \mathrm{~mm}\end{array}$ & $\begin{array}{c}4^{\circ}-\text { Fibra } \\
6 \mathrm{~mm}\end{array}$ & $\begin{array}{c}5^{\circ}-\text { Fibra } \\
12 \mathrm{~mm}\end{array}$ & $\begin{array}{c}6^{\circ}-\text { Fibra } \\
12 \mathrm{~mm}\end{array}$ & $\begin{array}{c}\sum \text { Fachada } \\
(\mathrm{cm})\end{array}$ \\
\hline Leste & 109,0 & 116,0 & 12,5 & 7,0 & 37,5 & 13,5 & 295,5 \\
\hline Oeste & 121,0 & 104,5 & 11,5 & 6,0 & 13,0 & 0,0 & 256,0 \\
\hline$\sum$ Painel $(\mathrm{cm})$ & 230,0 & 220,5 & 24,0 & 13,0 & 50,5 & 13,5 & - \\
\hline
\end{tabular}

Entre as argamassas com adição de fibras, a que obteve o melhor resultado durante os 28 dias, foi a argamassa contendo a fibra de $6 \mathrm{~mm}$, indicando ser esta a mais adequada para a redução da fissuração, seguida pela fibra de $12 \mathrm{~mm}$, que apresentou um bom resultado, mas em menor intensidade. Quanto a orientação solar em relação ao comprimento total de fissuras, as fachadas lestes dos painéis foram as mais afetadas.

Quando analisados os resultados do ensaio de susceptibilidade à fendilhação com os ensaios de resistência mecânica à compressão axial e à tração na flexão, percebe-se não haver uma correlação muito clara com as fissuras, pois de modo geral, a argamassa de referência apresentou maiores resistências que às argamassas com fibras, e ao mesmo tempo, sofreu mais com o surgimento de fissuras.

Entretanto, quando comparado com o ensaio de resistência de aderência à tração, observou-se uma correlação direta, uma vez que as argamassas com fibras obtiveram as maiores resistências e isto se correspondeu nas observações dos painéis, em que aqueles que foram revestidos com argamassa contendo as fibras de ambos os comprimentos, apresentaram baixa fissuração dos revestimentos. 


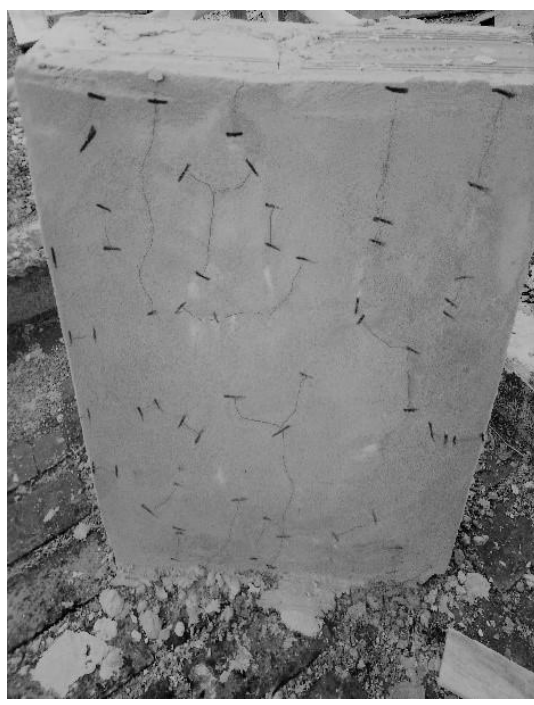

(a)

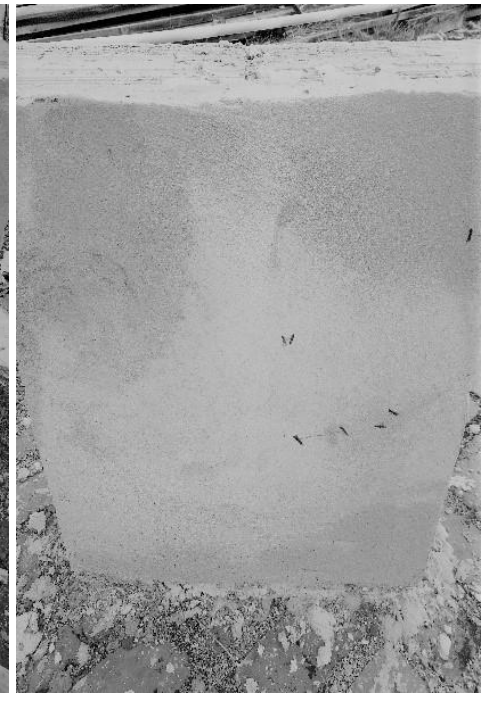

(b)

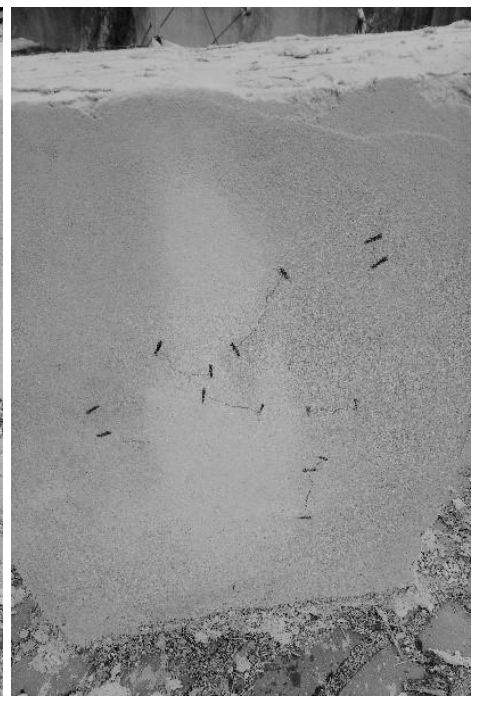

(c)

Figura 2: Pior situação de cada painel com argamassa de referência (a), fibra de $6 \mathrm{~mm}$ (b) e fibra de $12 \mathrm{~mm}$ (c), ao final dos 28 dias

\section{CONCLUSÕES}

Após análises dos resultados, observou-se que a mistura contendo adição de fibras de 6 mm apresentou melhor desempenho com a matriz cimentícia.

Nos ensaios mecânicos, as fibras ocasionaram uma redução na resistência dos compósitos, quando avaliados à tração na flexão e compressão axial (CPs prismáticos), comparados a argamassa de referência, contradizendo afirmações de Paliga et al. (2013), que afirmavam que as fibras proporcionavam maiores resistências mecânicas aos compósitos. No entanto, a argamassa contendo fibras de $6 \mathrm{~mm}$ apresentou os melhores resultados à compressão de corpos cilíndricos.

Quanto ao ensaio de aderência à tração, as fibras auxiliaram para obtenção das maiores resistências ao arrancamento. As fibras também ajudaram na redução da absorção de água nas amostras.

Por fim, as fibras foram fundamentais para prevenção do surgimento de fissuras. Ao final dos 28 dias, o comprimento total de fissuras dos painéis contendo as fibras foi cerca de $80 \%$ inferior aos painéis com argamassa de referência.

Os resultados de resistência mecânica dos corpos de prova não apresentaram correlação muito clara com as fissuras. Já nas resistências de aderência à tração, observou-se uma correlação direta. As misturas com adição de fibras obtiveram resultados mais altos de resistência à aderência, apresentando revestimentos de baixa fissuração.

Nos painéis com fibras de $12 \mathrm{~mm}$, foram observados agrupamentos de fibras, mostrando dificuldade de mistura neste comprimento de material. Somando este fato às mais baixas resistências mecânicas entre as argamassas analisadas, pode-se afirmar que este comprimento de fibra não se apresenta adequado para este tipo de aplicação.

De maneira geral, as fibras de $6 \mathrm{~mm}$ apresentaram o melhor desempenho em comparação com as demais situações estudadas a fim de reduzir a fissuração em argamassas de revestimento.

\section{AGRADECIMENTOS}

À empresa Macaferri do Brasil, por ceder as fibras para este estudo e à Unochapecó, pela seção dos espaços e estrutura necessária para esta pesquisa.

\section{REFERÊNCIAS}

ASSOCIAÇÃO BRASILEIRA DE NORMAS TÉCNICAS. NBR 7211: Agregados para concretos - Especificação. Rio de Janeiro, 2009. 
ASSOCIAÇÃO BRASILEIRA DE NORMAS TÉCNICAS. NBR 7215: Cimento Portland - Determinação da resistência à compressão. Rio de Janeiro, 1996.

ASSOCIAÇÃO BRASILEIRA DE NORMAS TÉCNICAS. NBR 7217: Agregados - Determinação da composição granulométrica. Rio de Janeiro, 1987.

ASSOCIAÇÃO BRASILEIRA DE NORMAS TÉCNICAS. NBR 13276: Argamassa para assentamento e revestimento de paredes e tetos - Preparo da mistura e determinação do índice de consistência. Rio de Janeiro, 2002.

ASSOCIAÇÃO BRASILEIRA DE NORMAS TÉCNICAS. NBR 13279: Argamassa para assentamento e revestimento de paredes e tetos - Determinação da resistência à tração na flexão e à compressão. Rio de Janeiro, 2005.

ASSOCIAÇÃO BRASILEIRA DE NORMAS TÉCNICAS. NBR 13528: Revestimento de paredes e tetos de argamassas inorgânicas - Determinação da resistência de aderência à tração. Rio de Janeiro, 1995.

ALMEIDA, A. E. F. S.; SICHIERI, E. P. Propriedades microestruturais de argamassas de cimento Portland com adições de minerais e poliméricas utilizadas na fixação de porcelanato. Cerâmica, v. 52, n. 323, pp. 174-179, Set. 2006.

MODRO, N. L. R. et al. Avaliação de concreto de cimento Portland contendo resíduos de PET. Revista Matéria, v.14, n. 1, pp. 725-736, Dez. 2009.

PALIGA, C. M.; REAL, M. V.; FILHO, A. C. Análise numérica de vigas de concreto armado reforçadas por compósitos formados por fibras de alta resistência e argamassa de cimento. Revista Ibracon de Estruturas e Materiais, v. 6, n. 2, pp. 211-226, Abr. 2013.

PIMENTEL, LIA L.; BERALDO, ANTONIO L.; JÚNIOR, HOLMER SAVASTANO. Durabilidade de compósito biomassa vegetal-cimento modificado por polímero. Tese (Doutorado em Engenharia Civil) - Universidade Estadual de Campinas, Campinas, 2006.

PINTO, NAYRA ALBERICI; FIORITI, CESAR FABIANO. Desempenho de argamassas de revestimento produzidas com borracha de pneus. Artigo (Mestrado em Engenharia Civil) - Universidade Estadual Paulista, São Paulo, 2016. 